\title{
0 terceiro setor e a democracia modificada: um estudo da mobilização civil contra a liberação dos transgênicos no B rasil
}

\author{
Ronaldo Martins Botelho*
}

\begin{abstract}
R esumo :Neste artigo, relacionamos o participacionismo e o minimalismo, dbis paradigmas democráticos contemporâneos, com as vigentes transformações nas economias capitalistas. Com base nisso, analisamos o papel do terceiro setor na mobilização social contra a liberação comercial dos transgênicos ${ }^{1}$ no B rasil. 0 estudo detém-se entre 1998 e 2001, ano em que o M PF/DF suspendeu as autorizações indiscriminadas para o cultivo de organismos geneticamente modificados (OGM s) no país, e privilegia o Estado do R io G rande do Sul, o qual consideramos pioneiro na mobilização contra os transgênicos.
\end{abstract}

Palavr as-chave: democracia, terceiro setor, participação política.

Questões em torno da liberação do cultivo e da comercialização de organismos geneticamente modificados (OGMs) no Brasil têm produzido, ao longo dos últimos anos, polêmicas discussões, nas quais se envolvem cada vez mais atores sociais. Se, na primeira metade dos anos 90 , quando foram encaminhadas à Câmara dos Deputados as primeiras solicitações de liberação de cultivos transgênicos, o debate sobre esse tema restringia-se às altas esferas científicas e políticas do país, progressivamente, conforme lideranças da sociedade civil assumem bandeiras de mobilização pela preservação da segurança sanitária e ambiental, os transgênicos adquirem maior cobertura pel os meios de comunicação e passam a despertar mais interesse da opinião pública. Da mesma forma, em sentido inverso,

\footnotetext{
* Bacharel em Comunicação Social pela Universidade Federal do Rio Grande do Sul, mestrando em Ciências Sociais pela Universidade Federal de São Carlos (SP) e professor do curso de J ornalismo da Fundação Faculdade da Cidade de União da Vitória (PR).

1. Transgênico é um vegetal em que foi implantado um gene (segmento celular) de outro ser vivo, que, com isso, transfere algumas de suas qualidades para a planta inoculada.
}

na medida em que a imprensa amplia a sua abordagem sobre esse assunto, aumenta 0 contingente de interessados nos motivos e implicações da possível adoção definitiva dessa tecnologia em escala comercial no país, gerandose, assim, novos enfoques e problemáticas a serem elucidadas.

Com o projeto de biossegurança, ${ }^{2}$ que está próximo a ser votado no Senado, o governo federal pretende encerrar a polêmica sobre esse assunto, que há quase uma década vem sendo motivo de controvérsias entre membros dos três poderes. Porém, a lei que vai regular a produção,

\footnotetext{
2. Projeto que vai regular a produção, pesquisa e venda de OGM s no Brasil. Pinheiro explica que há dois tipos de conceitos sobre biossegurança: a de processo e a de produto. Embora repare que o primeiro tipo seja mais interessante aos países em desenvolvimento, por privilegiar o meio, esse autor observa também que, "diante do avanço do Mercado sobre a Ciência e conseqüente diminuição da influência do Estado Nacional", a sua adoção torna-se "ultrapassada e benéfica às empresas privadas internacionais" (Pinheiro, 1999, p. 69). A biossegurança dos OGM s é prevista em vários tratados internacionais, como a Convenção de $\mathrm{Di}$ versidade Biológica (CDB), assinada pelo Brasil em 1992, e o Protocolo de Montreal, elaborado em 2000.
} 
pesquisa e venda de organismos geneticamente modificados no B rasil, para evitar que o governo continue lançando mão de medidas provisórias para legislar sobre a questão, não tem conquistado o necessário consenso entre os parlamentares da Câmara e do Senado. A polêmica em torno de sua aprovação, que pode depender do respal do de quatro comissões, reflete a complexidade do tema, que exige a combinação de informação e prudência, já que não há ainda segurança absoluta sobre a existência ou não de riscos ambientais e sanitários para o ser humano e a natureza no cultivo e consumo de transgênicos.

Neste artigo, concentramo-nos em um dos atores principais do debate nacional desenvolvido em torno desse assunto, e que tem sido decisivo para inúmeras decisões judiciais favoráveis à precaução na desregulamentação dos transgênicos: o terceiro setor, instância formada por organizações não-governamentais e sem fins lucrativos, que tem se expandido significativamente como espaço de organização e de ação da cidadania entre os brasileiros. A análise privilegia os eventos ocorridos no estado do R io $G$ rande do Sul, durante a primeira metade da década de 1990. Nesse período, atuamos na assessoria da subsede gaúcha da Confederação Nacional dos Trabalhadores da Alimentação (Contac), entidade ativa na questão dos transgênicos. Tendo como ponto de partida a caracterização de duas diferentes tendências que marcam a construção da democracia representativa, desde o modelo clássico até a sua revisão crítica no século $X X$, avaliamos, através deste estudo, al gumas fal has e desequilíbrios que se apresentam na consolidação desse regime no B rasil. N otamos que a deficiência nos instrumentos de controle, transparência e equilíbrio, em momentos de decisões estratégicas, fragilizam a conduta das autoridades políticas e podem prejudicar a necessária isenção do poder público oficial. Tais deficiências tanto podem decorrer da orientação ideológica de governo, como de supostas certezas advindas de posicionamentos científicos imprudentes. ${ }^{3}$

3. Nesse ponto, é importante destacar um discurso difundido por pesquisadores que consideram o cidadão comum como desinteressado ou inapto para posicionar-se sobre questões complexas. Trata-se da queixa de que a resistência à libera-
Nesse sentido, a intervenção da sociedade civil organizada, através de instrumentos legais, políticos e recursos comunicativos, representa um fator de tensionamento do jogo político, capaz de redimensionar a ação dos governantes no sentido de contemplar os interesses majoritários da sociedade. Assim, pretendemos apontar al guns mecanismos que determinam a dinâmica dessa reconfiguração de forças no regime democrático representativo, a partir da emergência do terceiro setor.

\section{M inimalismo $\mathrm{x}$ participacionismo}

U m choque estrutural abalou no século $X X$ o arcabouço teórico da concepção histórica da democracia como forma de expressão legítima do povo. A concepção minimalista, desenvolvida por J oseph Schumpeter em Capitalismo, socialismo e democracia, será a base dessa contraposição à democracia como ideal ${ }^{4}$ (Schumpeter, 1961, p. 327). A o fundamentar uma teoria que reduz esse modelo a um arranjo institucional no qual os grupos disputam a escol ha do el eitor, Schumpeter reduz a função do jogo democrático à esfera política, desafiando a concepção clássica até então hegemônica, que sustenta que a função da democracia seria a concretização da vontade coletiva e o bem comum através da expressão soberania popular - ideais preservados desde autores clássicos como Hobbes e R osseau.

Desde a emergência de sua teoria, em meados do século $X X$, Schumpeter provocou um profundo debate nas ciências políticas,

ção comercial dos transgênicos significa um "impedimento ao progresso da ciência". No caso em questão, esta configura-se uma sentença simplista e suspeita, visto que, não raras vezes, tem sido utilizada para apoiar o interesse comercial de empresas privadas. Como se a ciência fosse seguramente alienada de interesses políticos e dispensada de prestar contas à sociedade e às futuras gerações.

4. Para sustentar o seu conceito, Schumpeter realiza uma crítica à definição clássica, que atribui à democracia o papel de expressão da vontade coletiva. Primeiramente, ele observa que a vontade coletiva não é fruto de uma escolha racional, mas obedece a impulsos emotivos. Em função da desigualdade cultural, os indivíduos têm interesses diferenciados. Além do mais, esse autor transpõe para a política noções econômicas de formação da demanda para justificar sua tese de que as decisões individuais na democracia sofrem interferência de fatores extras. Supondo, a partir disso, que não existe essa vontade individual, o autor sustenta igualmente a impossibilidade de existência de vontade geral. 
gerando uma divisão entre seguidores e contestadores. Seguindo a sua esteira teórica, e a ela agregando novos conceitos analíticos, Dahl, Downs e OIson identificaram-se com a teoria minimalista. Esses autores acrescentaram novas contribuições à corrente que propôs distanciar a democracia do compromisso com valores e objetivos, excluindo ou diminuindo o papel do povo como sujeito no processo democrático.

Em um sentido diferente trilharam outros teóricos, desenvolvendo estudos em direção a um aprofundamento crítico-propositivo da teórica minimalista, compondo, assim, um outro grupo, que veio a ser denominado de participacionistas. Peter Bachrach, Carole Pateman e $C$ raw ford $B$ rough $M$ acpherson, entre outros, são identificados com esse campo. A idéia básica que guiou essa última corrente foi a de que a democracia deve ser entendida como meio de atingir fins públicos e como processo de participação, através do qual é possível ao homem comum desenvolver determinadas habilidades.

Entre os minimalistas, para demonstrar que nenhum dos model os encontrados na real idade é totalmente democratizado ou totalmente responsivo aos cidadãos - sendo necessária uma classificação intermediária -, R obert Dahl desenvolve o conceito de poliarquia (Dahl, 1997, p. 31). A nthony Downs, por sua vez, em U ma teoria econômica da democracia, inaugura a teoria da escolha racional, que tem como pilares fundamentais para o entendimento acerca do funcionamento da democracia o caráter competitivo do método democrático e a pressuposição da racionalidade dos agentes políticos. D ando um passo à frente nesses estudos, em A lógica da ação coletiva (1999), Mancur Olson realiza uma análise na qual 0 comportamento individual e coletivo éinterpretado no contexto da democracia contemporânea com base na teoria da escolha racional.

Em direção oposta à esteira teórica traçada por Schumpeter, que via o homem comum como limitado para o envolvimento em determinadas instâncias de poder - exclusivas aos mais capacitados - , os partici pacionistas vão comungar o entendimento de que a participação é um canal não apenas viável de integração dos indivíduos aos mecanismos de decisão pública, como necessário para que estes evoluam através da prática política. N essa perspectiva, é possível conceber uma esfera da democracia que se situa em uma órbita muita mais complexa do que o simplificado modelo que reduz esse regime a uma concorrência de grupos privados capazes, através da manipulação da vontade coletiva, em vista da direção do controle burocráticoadministrativo do Estado.

Em The theory of democratic elitism - a critique, Peter $B$ achrach critica o que denomina deelitismo democrático, construindo um modelo alternativo, que entende a participação como algo possível na democracia contemporânea. Carole Pateman, por sua vez, em seu livro Participação e teoria democrática, sustenta a existência de um caráter pedagógico na participação. Conforme essa perspectiva, 0 indivíduo, ao participar, desenvolveria alguns atributos que o levariam a engajar-se cada vez mais (Pateman, 1989). M acpherson, finalmente, anal isa a partici pação sob um ol har mais cauteloso elimitado. Sustentando a convivência desta com o modelo representativo, propõe uma alteração na sociedade e na consciência dos homens para a ampliação dos canais de ação direta na democracia (M acpherson, 1978, p. 102-103).

A utores posteriores el aboraram novas críticas aos limites do modelo minimalista. U ma leitura sobre as origens dessa divisão no paradigma democrático remete a duas grandes significações que a democracia assumira em um passado remoto, e que vieram a se fundir nos dias atuais: a democracia do povo e a democracia dos políticos. Conforme José Nun, 0 primeiro modelo teria a sua origem em $A$ tenas, pensada como expressão efetiva da vontade geral. Já o governo dos políticos teria como berço a G récia, onde a participação popular era inspirada como suporte ao governo dos políticos. N OS dias atuais, essas duas correntes ter-se-iam confluindo em uma grande 'família', predominante nas sociedades ocidentais e que convivem, embora não de forma pacífica ou harmoniosa.

Observa esse autor que o pensamento único imposto pela democracia liberal no mundo, sustentado por uma aversão quase dogmática à intervenção do Estado na economia e na impossibilidade de reação contra a globalização, paralisou a reação mundial ao modelo hegemô- 
nico. Sem desconsiderar os avanços da democracia representativa e as instituições desenvolvidas em seu bojo, Nun pensa que é urgente uma retomada do senso crítico, pelos trabal hadores - que são os agentes mais legítimos para discutir o futuro da democracia -, a fim de inserir na agenda política a conscientização sobre a necessidade de ampliar a órbita de participação social, que excluiu milhões de trabal hadores, por imposição de uma lógica que separa a economia da política (N un, 2000, p. 19-22; 167-175).

Tendo em vista esse recorte participacionista resgatado nos estudos políticos contemporâneos, examinamos, a seguir, a democracia representativa no panorama mundial, levando em conta os novos contornos assumidos pelos Estados nacionais diante da ampliação do poder de abrangência das grandes empresas transnacionais. Esse olhar é necessário para visualizarmos os limites que se impõem para a intervenção da sociedade civil nos assuntos públicos nas democracias capitalistas, bem como as possibilidades ainda existentes de reação à lógica excludente do capital sobre as instituições democráticas nos países emergentes.

\section{Democracia, estado e capitalismo}

A democracia liberal tem ampliado a sua hegemonia pelo mundo, em grande medida, através da expansão do capital ismo. Embora se saiba que esse sistema seja muito mais recente que a democracia, é também reconhecido que o capital ismo se desenvolve com mais plenitude nas sociedades democráticas. $M$ as a recíproca dessa sentença não é necessariamente verdadeira ${ }^{5}$ (O uthwait \& Bottomore, 1996, p. 179). Isso porque o capitalismo, em sua fase global, dotou as instituições econômicas de instrumentos de planejamento e controle econômico que transcendem a esfera nacional, um poder político que gera influência nas instituições democráticas estrangeiras, promovendo desigual dades no jogo

5. Assim é, se entendermos o conceito de democracia com base em sua significação genuína, na qual o demos, desde Heródoto, implica possibilitar ao povo decidir sobre o essencial naquilo que Ihe diz respeito. Em termos mais claros, traduzidos nas palavras de A. Lincoln, o "governo do povo, pelo povo e para o povo". de forças entre os atores políticos nacionais e, conseqüentemente, 0 desequilíbrio nas democracias nacionais (B orón, 2001, p. 174).

A emergência de novos campos e canais globais de relações comerciais no campo econômico, de fato, exige níveis mais abrangentes de articulação da sociedade civil. Porém, a idéia de que essas transformações nas formas organizativas de resistência redefinem o espaço público como órbita de intervenção da sociedade civil é uma noção que não atribui o devido valor ao Estado na configuração do campo de conflitos que cercam as lutas pelo interesse público. Condizente com essa avaliação, $\mathrm{M}$ attelart ${ }^{6}$ observa que "a sociedade civil é indissociável do território nacional". Para esse autor, além de principal referencial na defesa do interesse geral, o Estado tem como principal função a de não deixar que o mercado total se instale.

Por outro lado, o Estado, como ente conciliador dos conflitos sociais em prol do atendimento das demandas públicas, não é uma instituição neutra na órbita da disputa de interesses que marcam cada renovação dos quadros governamentais. A gentes políticos internos e externos dividem as atribuições de um governo entre a atenção às questões sociais e as aspirações políticas típicas da carreira pública, contaminando o jogo el eitoral com a exclusão de alguns setores em detrimento de outros das benesses passíveis de distribuição através do aparel ho administrativo estatal .

Cedendo a políticas de ajuste estrutural impostas pel os países centrais, através da negociação de dívidas monumentais intermediadas por organizações supostamente multilaterais, como o FM I e o B anco M undial, os governos nacionais dos países periféricos abrem os seus mercados à interferência direta e indireta de transnacionais estrangeiras. Isso se traduz em forte influência nas economias nacionais por parte das matrizes centrais dessas empresas, sediadas nacional mente, mas investidas de quase ilimitada mobilidade geográfica.

0 livre fluxo dos mercados e a mobilidade crescente dessas megacorporações, que se

6. Em entrevista à revista Caros Amigos, p. 40-43, n. 39 jun./2000. 
estende ao plano político nas democracias capital istas, contribuem para o desenvolvimento de uma cultura institucional marcada pela preponderância do privado sobre o público. Essa mercantilização da vida social tem na filosofia do Estado M ínimo a sua principal ideologia de expansão, e no controle dos mercados nacionais pelas megacorporações privadas o seu principal meio de difusão. Tal ordenamento constrói sistemas de valores que privilegiam o consumo em detrimento da cidadania e legitima, por intermédio das próprias instituições democráticas - ora enfraquecidas pelos novos Leviatãs ${ }^{7}$-, uma espécie de ditadura burguesa. N ela, o voto do mercado tem mais mobilidade, atualidade e eficácia que as formas de manifestações políticas do cidadão comum, já que os mercados, diferentemente dos eleitores, "votam todos os dias" (B orón, 2001, p. 193-194).

Foi nesse panorama marcado pela emergência dos novos $L$ eviatãs que, no final dos anos 80 , começou a surgir no país uma forte pressão internacional, capitaneada pelo A cordo Geral de Preços e Tarifas (Gatt), favorável à aprovação do novo Código de Propriedade Intelectual. A pesar da intensa discussão no Congresso Nacional, o B rasil acabou cedendo a pressões externas, especialmente dos Estados Unidos, e aprovando esse novo código. N essa nova legislação, foram propostas três grandes mudanças nas áreas de software, indústria farmacêutica e patenteamento de seres vivos. ${ }^{8}$

Explorando um discurso baseado na necessidade do "aumento da produtividade por área",

7. De acordo com Borón (2001), os novos Leviatãs são atores políticos de primeira ordem nas economias capitalistas contemporâneas. Diferentemente do L eviatã hobbesiano, que garantia a ordem social através de um contrato entre os indivíduos, os novos Leviatãs, representados pelas grandes transnacionais, orientam as políticas nacionais e desequilibram as democracias.

8. Essa política, caracterizada pela abertura comercial, correspondia a grandes interesses de transnacionais do setor agro-alimentar. A empresa Monsanto, por exemplo, através da liberação comercial de suas sementes patenteadas, poderia impor aos agricultores brasileiros os seus pacotes tecnológicos, com a venda de suas sementes transgênicas condicionalmente 'casadas' a um respectivo herbicida, sendo ambos produtos de propriedade comercial de um mesmo e único fornecedor. Em outras palavras, significa isso a dependência absoluta do agricultor com relação a uma empresa específica. Ver: Transgênicos: uma questão estratégica. Adverso, Jornal da ADUFRGS, Porto A legre, n. 67, ago./ 2000, p. 6-7. para evitar uma ameaça à humanidade com um futuro "déficit na produção mundial de alimentos" ${ }^{9}$ e da suposta conquista de novos mercados externos, proporcionada pela produção dos transgênicos, a transnacional norte-americana M onsanto logrou êxito em conquistar o apoio de importantes parcelas da comunidade científica brasileira e de representantes públicos como o M inistério da A gricultura e o próprio então presidente Fernando Henrique Cardoso, durante as suas duas gestões (1995-1998 e 19992002).

Declarações veiculadas na imprensa em setembro de 1998, por duas importantes autoridades científicas governamentais, atestam esse respaldo. N esse período, o então presidente da Embrapa, Alberto Duque Portugal, declarava estar "convencido de que o B rasil deve seguir os passos de outras regiões do mundo que já experimentaram as plantas transgênicas. [...] é uma questão de se ajustar a uma tecnologia que deve se consagrar no próximo milênio" (Zero Hora, Caderno Campo \& Lavoura, 14/9/1998, p. 26). Praticamente uma semana depois, era a vez do então presidente da CTN bio, L uiz A ntônio $B$ arreto de $C$ astro, anunciar o seu parecer favorável à soja da M onsanto, que declarava "não haver risco de al opolinização com outras espécies de sojas produzidas no Brasil", ao mesmo tempo em que técnicos de entidades como 0 Instituto de Defesa do Consumidor (I dec) e o Greenpeace denunciavam vários problemas que esse tipo de cultivo poderia suscitar, como al ergias ao corpo humano e futura dependência tecnológica dos agricultores brasileiros (Zero Hora, Caderno Campo \& Lavoura, 25/9/1998, p. 36).

A nalisamos melhor a seguir essa investida das transnacionais alimentícias sobre o Estado brasileiro, visando à expansão de seus mercados, assim como as conseqüentes reações da sociedade civil. Nesse propósito, vamos primeira-

9. 0 mesmo discurso serviu de base para a defesa dos agrotóxicos durante a 'Revolução Verde' nas décadas de 1960 e 1970. Ver: PATERNIANI, Ernesto \& AZEVEDO, João Lúcio. Salvando o planeta com alta tecnologia agronômica. Ciência Hoje, v. 21, n. 122, Jun./1996 e Transgênicos: problema técnico e não político (carta aberta de J osé A. Lutzemberger à CTN bio). Fundação Gaia, 14.8.1998. In: www.A girazul.com.br - A rtigos. 
mente caracterizar brevemente o chamado terceiro setor, já que, no caso da mobilização contra a liberação comercial dos transgênicos, consideramos ser essa a principal instância na qual os cidadões brasileiros se organizam e ampliam a sua participação no jogo democrático.

\section{Os transgênicos e o terceiro setor}

$\mathrm{N}$ a definição de Lester Salamon, o terceiro setor representa

uma virtual revolução associativa que está em curso no mundo, fazendo emergir um Terceiro Setor Global, que é composto de: a) organizações estruturadas; b) localizadas fora do aparato formal do Estado; c) que não são destinadas a distribuir lucros auferidos com suas atividades entre os seus diretores entre 0 conjunto de acionistas; d) autogovernadas; e) envolvendo indivíduos num significativo esforço voluntário. (A pud Fernandes, 1994, p. 19 e 88)

As ONGs, que juntamente com os movimentos sociais constituem hoje a principal al avanca de mobilização das classes populares no terceiro setor, tornaram-se um fenômeno massivo no continente americano desde a década de 1970. Entretanto, de acordo com M ontenegro (1994, p. 7), a denominação 'ONG' ampliou efetivamente a sua popularização no B rasil a partir da ECO 92, quando várias ON Gs com fins ecológicos realizaram um encontro paral el o com al guma cobertura na mídia.

$M$ ais recentemente, a participação popular da sociedade civil organizada nos três primeiros Fóruns Sociais M undiais, realizados em Porto A legre (RS), demonstraram a imensa amplitude do papel político das ONGs no mundo. Esse evento demarcou também a disposição dessas organizações de consolidarem políticas nacionais e planetárias, por intermédio da intervenção local, parcerias com governos progressistas e, sobretudo, através de uma rede mundial contrahegemônica capaz de ampliar os limites da democracia representativa.

Diante das pressões de grandes multinacionais do setor alimentício pela liberação dos transgênicos no Brasil, as ONGs têm tido um papel exemplar de independência e vigilância do cumprimento das normas de segurança da saúde pública e do meio ambiente, papel este não poucas vezes insatisfatoriamente cumprido por parte do Estado. A o contrário, importantes setores governamentais, dotados dos seus meios burocráticos formais e, sobretudo, apoiados pela sua legitimidade, lançaram mão de recursos disponíveis para desqualificar as reações da sociedade civil organizada contra a pressa pela desregulamentação dos transgênicos.

É preciso observar, entretanto, que, em uma sociedade capitalista, a garantia de liberdades políticas equivalentes em um espectro de meios materiais desigual mente distribuídos (Saes, 1993, p. 72-73) possibilita também que setores do terceiro setor convertam-se em canais de intervenção voltados para interesses estritamente privados. No B rasil, em particular, há um campo fértil para isso, considerando que a cidadania é caracterizada em nosso país por uma espécie de divisão social entre os "cidadãos doutores", os "simples cidadãos" e os "cidadãos elementos" (Nun, 2000, p. 131).

Todavia, independentemente do perfil político das organizações que se integram a sua esfera, o terceiro setor já é reconhecido como uma instância de alto potencial político. Particularmente nos países periféricos, onde as demandas sociais inadequadamente atendidas pelo Estado abrem múltiplas brechas para a intervenção da sociedade civil através da organização voluntária, a extensão e a profundidade de mobilização do terceiro setor são crescentes. ${ }^{10}$

U ma das mais polêmicas solicitações de autorização para o plantio comercial de cultivo de natureza transgênica no Brasil foi encaminhada à Comissão Técnica Nacional de Biotecnologia (CTN bio) ${ }^{11}$ em 1998, pela empresa norte-americana M onsanto, requerendo a desregulamentação de sua soja Roundup

10. Conforme dados de um estudo feito pela Hopkins University e o Instituto Superior de Estudos da Religião (Iser), haveria no Brasil 220 mil entidades, institutos, associações, fundações e organizações diversas atuando no terceiro setor. Nesse universo, destinado à prestação de serviços à comunidade, estariam engajados doze milhões de voIuntários, número suficiente para povoar todo o Equador. Ver: Revista Problemas Brasileiros, jan./fev., 2000.

11. A CTNbio, criada no governo Fernando Henrique, em janeiro de 1995, é o órgão do governo federal que fiscaliza a pesquisa de organismos geneticamente modificados (OGM s) no Brasil. 
Ready. ${ }^{12}$ Desde então, visando capitanear apoio político para a empreitada se expandir comercialmente, a Monsanto desencadeou uma pesada campanha política ejurídica direcionada a instituições de pesquisa, universidades, cientistas, agricultores e, especialmente, a parlamentares brasileiros vinculados às chamadas bancadas ruralistas. A alta patente dos pesquisadores selecionados para compor a CTN bio não impediu que esse organismo fosse criticado desde a sua origem. Um dos questionamentos realizados com relação àquele órgão era o seu vínculo institucional com o M inistério da Ciência e Tecnologia, quando se consideram os M inistérios da Saúde e o da A gricultura muito mais competentes para esse tipo de atribuição.

A partir de 1998, em resposta à pressa e a quase nenhuma cobertura da imprensa sobre 0 debate científico sobre esse assunto, lideranças ambiental istas iniciam uma discussão paralela à das altas instâncias científicas, buscando difundir informação sobre essa questão entre outros interessados, al ém dos executivos de multinacionais, dos al tos escalões do governo federal e dos pesquisadores que os assessoravam. E 19 de fevereiro daquel e ano, a M onsanto do B rasil realiza no Everest Hotel - um dos mais suntuosos da capital gaúcha - um coquetel de lançamento de sua soja Rondup R eady. L ideranças da área sindical e ambiental são convidadas para a cerimônia, mas poucos se fazem presentes. Entre os participantes, constrói-se o consenso sobre a necessidade de uma ação imediata que garantisse uma maior democratização da informação sobre os transgênicos.

U ma das iniciativas mais ilustrativas dessa mobilização nesse período foi o seminário Biotecnologiae Produtos Transgênicos, realizado por meio de uma parceria entre a U niversidade Federal do Rio Grande do Sul (UFRGS), a U nião Internacional dos Trabalhadores daA limentação (Uita), a Confederação Nacional dos TrabaIhadores da Alimentação (Contac) e o Grupo de Pesquisa e A ção em Agricultura e Saúde

12. Conforme 0 processo protocolado na CTNbio pela M onsanto em 29/6/1998, a desregulamentação implica "a livre prática de atividades, de cultivo, registro, uso, ensaio, testes, transporte, armazenamento, comercialização, consumo, importação e descarte da referida soja". Ver: www.mct.gov.br - Documentos.
(Gipas). 0 evento reuniu, entre os dias 7 e 8 de abril de 1998, aproximadamente oitocentas pessoas no H otel Embaixador, em Porto A legre. Ali, estudantes, cientistas, executivos, sindical istas e ambientalistas puderam aprofundar 0 debate e esclarecer dúvidas sobre esse tema com os mais diversos setores interessados.

É também a partir desse período que começa a se intensificar no país a guerra jurídica em torno dos transgênicos, com decretos, liminares, recursos e processos contra e a favor à liberação do cultivo e comércio desse tipo de alimento. Desde então, os representantes do Estado, em seus vários poderes, de certa forma dividiram-se em torno de identificações comerciais, ambientais, políticas, religiosas e ideológicas. Entre os anos de 1997 e 1998, a CTN bio deferia cerca de oitocentos pedidos de liberação de OGM s no meio ambiente (M enasche, 2000 , p. 524). No caso do pedido de liberação comercial da soja Rondup Ready, da Monsanto, o engenheiro agrônomo Sebastião Pinheiro, pesquisador do Gipas, aponta a falta de seriedade e questiona a independência da CTN bio na aval iação já no primeiro pedido dessa multinacional, em junho de 1998, para a liberação de sua soja transgênica:

Não estranhamos quando a CTN bio recebeu apressadamente 0 processo [...]. 0 mais estranho é que o processo começa por um ofício resposta a uma carta da CTN bio, que não consta no mesmo, nem se conhece o teor, mas pode-se suspeitar que o presidente da comissão avisasse a empresa, para dar andamento, antes que al guma medida legal impedisse a tramitação. (Pinheiro, 96, p. 1999)

Em resposta ao forte e apressado looby de empresas estrangeiras - como a M onsanto, Du Pont, N ovarts, Syngenta... - para a liberação do cultivo e comércio de al imentos transgênicos, inúmeras entidades adotaram como estratégia esclarecer a opinião pública sobre a postura flexível do governo do B rasil com relação a essa questão, denunciando a suposta conivência da CTN bio com o setor privado. A inda em setembro de 1998, após longos debates nos meios científicos, políticos e na sociedade civil organizada - ainda que com muito pouco reflexo entre a grande massa da população - , a CTNbio 
determina a liberação comercial da soja R ondup Ready, considerando não haver risco ambiental para a saúde e o meio ambiente.

A pesar de tal parecer, uma liminar concedida pela Justiça Federal à ONG norteamericana Greenpeace e ao Instituto de D efesa do Consumidor (Idec) proibiu o governo federal de liberar a comercial ização da soja transgênica da M onsanto. Indo mais longe, o Idec entrou com uma ação contra a U nião, exigindo, entre outros pedidos, que a CTN bio anulasse o parecer técnico-científico que concedera àquela empresa. Entre os principais questionamentos do Idec em sua liminar protocolada contra a decisão da CTN bio, favorável à M onsanto, destacava-se a falta de instruções normativas sobre segurança alimentar, rotulagem e comercialização. Segundo aquela entidade, tais questões não teriam sido discutidas e aprovadas pela CTNbio antes da emissão de seu parecer a respeito desse tema (Zero Hora, 25/9 e 17/10/1998).

Há circunstâncias em que as instâncias fiscalizatórias formais com que conta a democracia representativa, que integram a órbita institucional do Estado - o Senado, o Congresso e o Poder J udiciário - , apresentam-se vulneráveis à contaminação por influências de interesses contrários ao interesse público. Esse desequilíbrio no poder fiscalizatório das instituições democráticas constituídas pode ocorrer por vias que vão desde campanhas de orientação da opinião pública através dos meios de comunicação de massa nacionais - que com facilidade tendem a reproduzir as vozes políticas hegemônicas no panorama internacional ${ }^{13}$ - até pesados lobbies internos realizados por corporações transnacionais.

A parte o reconhecimento dessa vulnerabilidade do aparelho estatal e de seus agentes nas democracias capitalistas, é reconhecido por autores contemporâneos que há uma natureza plural nas sociedades capital istas que não admite a mera imposição de uma agenda uniforme por parte das instâncias públicas institucionais, havendo, inclusive, possibilidades concretas da

13. Para uma abordagem mais profunda sobre o papel da imprensa na definição de agendas, ver: MIGUEL, L uis Felipe. U m ponto cego nas teorias da democracia: os meios de comunicação. BIB, Rio Janeiro, n. 49, $1^{\circ}$ semestre de 2000, p. $51-77$ realização de transformações substanciais dentro ou fora de sua estrutura (J essop, 1990, p. 170195). N esse contexto, o denominado terceiro setor ocupa um espaço estratégico no sentido de encurtar as distâncias existentes entre os indivíduos excluídos do processo de tomada de decisões.

$\mathrm{Na}$ questão dos transgênicos no Brasil, desde o início de 1998 ganhava adesão no país a mobilização de diferentes setores sociais, pró e contra à liberação do cultivo de alimentos geneticamente modificados. A mbientalistas, produtores rurais, sindicatos, entidades empresariais, movimentos de donas de casa e outras organizações sociais passaram a constituir fóruns de discussões, conforme níveis de interesses específicos. ${ }^{14}$ A ssim, consolidava-se no país uma forte rede nacional que influenciou, apoiou e fiscalizou a condução de políticas públicas voltadas para a segurança al imentar: a campanha Por um B rasil L ivre deTransgênicos.

A rticulada naquele período, essa iniciativa foi integrada por várias organizações nãogovernamentais, entre elas: o Instituto de Defesa do Consumidor (Idec), a A ssessoria e Serviços a Projetos em A gricul turaA Iternativa (A S-PTA) (coord.), a A ctionaid B rasil (coord.), o Centro de Pesquisa e A ssessoria (Esplar) (coord.), 0 Instituto de Estudos Socioeconômicos (Inesc) (coord.), o Greenpeace, o Centro de Criação del magem Popular (Cecip), o Centro Ecológico I pê (Ce-Ipê) e a Federação dos Órgãos para A ssistência Social e Educacional (Fase). Esse movimento propunha-se a "disseminar idéias e informações sobre os impactos e riscos dos $0 \mathrm{r}$ ganismos G eneticamente M odificados (OGM s) no meio ambiente, na saúde do consumidor e na agricultura". ${ }^{15}$

Quando o Estado assume posturas independentes, contrariando pressões econômicas e

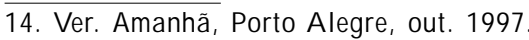

15. Ver: http://www.idec.org.br/paginas/campanha_transgenicos livre.asp. Durante o ano de 1998, outras organizações engajaram-se direta ou indiretamente nessa causa. Entre essas, a Sociedade Brasileira para o Progresso da Ciência (SBPC), o M ovimento dos Trabalhadores Rurais Sem Terra (MST), a Confederação $\mathrm{Nacional}$ dos Bispos do Brasil (CNBB) e a Confederação Nacional dos Trabalhadores na Alimentação (Contac/CUT). Essas entidades tiveram papel estratégico na inserção desse tema na agenda política brasileira e no conseqüente redimensionamento da legislação brasileira sobre essa questão. 
primando pelo interesse público, pode tornar-se uma instância legítima da vontade das vozes desassistidas, sendo, assim, um suporte importante às ações das organizações civis representantes da vontade popular. Em novembro de 1998, o governador gaúcho Olívio Dutra encaminha projeto de lei à A ssembléia L egislativa decretando o RS como "Á rea Livre de Transgênicos". A pesar da mobilização de importantes setores da sociedade civil organizada, deputados ligados ao agronegócio articulam-se e impedem a aprovação desse projeto.

E m janeiro de 1999, atendendo aos apelos de várias organizações civis, Dutra realiza um circuito de seminários regionais sobre transgênicos. Com base nas manifestações decorrentes desses eventos, e endossando o interesse de organizações civis, o deputado estadual gaúcho Elvino Bohn Gass apresenta à $A L$ do RS o projeto $16 / 99$, propondo a proibição, no Estado, do cultivo e da comercialização de organismos geneticamente modificados. A inda em maio deste ano, reunidos em Recife, 27 secretários estaduais presentes no Fórum Nacional de Secretários de A gricultura decidem, por unanimidade, aprovar uma moratória para a aprovação da transgenia no B rasil enquanto não fosse resolvido o impacto sobre os orçamentos nos estados e as incertezas nas pesquisas (M enasche, 2000, p. 9).

Em julho de 1999, a polêmica sobre os transgênicos torna-se a tônica na $51^{\text {a }}$ Reunião A nual da SB PC, realizada em Porto A legre. M as será somente em agosto daquele ano que a $6^{\mathrm{a}}$ Vara Federal, de B rasília, confirmará a sentença que suspende o plantio de soja transgênica no país até que seja apresentada o EIA-Rima. A pesar dessa decisão, e de outras impeditivas à introdução de organismos geneticamente modificados na agricultura e nas prateleiras dos supermercados brasileiros, os diferentes vieses que esse debate assumiu em variadas instâncias jurídicas, em um país de dimensões continentais como 0 B rasil, não permitiram aos órgãos de fiscalização do governo federal dispor de recursos financeiros nem humanos para fiscalizar todo o território brasileiro. A ssim, em novembro de 1999, treze equipes de fiscal ização da Secretaria da Agricultura do RS - em visita a duzentas propriedades rurais - apreenderam 3.588 sacas de soja transgênica. Este era um dos primeiros sinais de que a inflexibilidade das autoridades públicas federais, em momentos estratégicos, poderia comprometer qualquer política séria e unificada, direcionada à construção de um projeto tecnológico, eficaz e independente no campo da biotecnologia. Estigmatizados pelas suas posturas críticas à onda transgênica, muitos pesquisadores conceituados foram excluídos do centro das discussões sobre os transgênicos por discordar da orientação hegemônica no governo federal. Conforme Lewgoy,

Tais cientistas acreditam que, no devido tempo, amparada por pesquisas básicas já em andamento, equando e onde se fizerem necessárias, surgirá uma nova geração de organismos geneticamente modificados, que não trará servidão aos agricultores nem riscos desconhecidos à saúde e ao meio ambiente. Essa nova geração de organismos deve ser desenvolvida em instituições públicas, e não em empresas transnacionais. (2000, p. 508)

A pós sucessivas denúncias de cultivos transgênicos ilegais, em julho de 2000 o governo federal divulga nota oficial - assinada pelos ministros da Casa Civil, da A gricultura, da Ciência e Tecnologia, do M eio A mbiente e da Saúde - em que defende a adoção de organismos geneticamente modificados no país. Será a formalização, ainda no governo Fernando Henrique, da alienação do Estado brasileiro de sua função de vigilância sanitária e ambiental, sob o princípio da precaução. ${ }^{16}$ Porém, depois de uma longa e acirrada batalha jurídica e de informação, com liminares contra e a favor, em 27 de abril de 2001 o juiz substituto da $14^{a}$ Vara Federal do Distrito Federal deferiu liminar ao M inistério Público Federal suspendendo todas as autorizações para cultivo de qualquer sementes geneticamente modificadas, sem 0 Registro E special Temporário (RET). ${ }^{17}$

A partir de março de 2002, já na gestão do presidente L uiz Inácio L ula da Silva, o governo

\footnotetext{
16. Este orienta que, quando uma atividade ameaça causar danos ao meio ambiente ou à saúde humana, medidas de precaução devem ser tomadas, mesmo que relações de causa e efeito não estejam plenamente estabelecidas cientificamente.

17. Ver o Estado de S. Paulo, p. A-14, 8 de julho de 2001.
} 
federal procura administrar os interesses conflitantes na questão dos transgênicos. Todavia, as agudas diferenças políticas visíveis entre ministérios estratégicos da ampla frente partidária que dá sustentação ao governo como o estímulo ao agronegócio na pasta da A gricultura, em contraponto ao fortal ecimento da agricultura familiar, defendida pela pasta do Desenvolvimento Fundiário - têm impedido a adoção de uma política clara, uniforme e eficiente na área de biotecnologia. M ais uma vez, o terceiro setor assume a dianteira através de ações propositivas em níveis ainda passíveis de controle público, como o cultivo seguro, estabelecendo-se co-responsabilidade dos fabricantes de sementes transgênicas por possíveis danos sanitários e ambientais, e a rotulagem, que possa permitir que o consumidor identifique e tenha a liberdade de escolher produtos de natureza transgênica.

\section{Consider ações finais}

A polêmica dos transgênicos demonstra que a sociedade civil organizada, expressada através do terceiro setor, assume um potencial de intervenção política que pode atuar sobre as instâncias de representação pública oficiais, de modo a fiscalizar ações de duvidoso interesse público, provocar o debate e inserir questões pertinentes na agenda política. Com isso, a sociedade civil assume um nível não mais passivo diante das instituições democráticas, mas al tamente participativo, capaz de propor, barrar ou reajustar determinações governamentais.

A o elaborar uma teoria democrática que concebe o jogo político como um processo em que os indivíduos comuns têm um papel restrito ao ato da escolha, Schumpeter ignora essas possibilidades de ação social. Esse potencial dinâmico das ON Gs pode influenciar, inclusive, na indicação dos representantes públicos como outra forma de expressão, independentemente do voto, e envolve outros agentes, além dos concorrentes e eleitores, nas escol has públicas. U ma participação ativa da sociedade civil permeia e influencia nas el eições, mas também se estende ao âmbito dos governos eleitos.

E $m$ vista de sua abordagem, que considera a democracia um arranjo institucional no qual os grupos disputam a escolha do eleitor, é comum identificar Schumpeter com a teoria dos pluralistas, dominante na literatura anglo-saxônica das décadas de 1950 e 1960. Entretanto, ao conceber essa identificação, os pluralistas fizeram ressalvas a respeito das limitações impostas por seu enquadramento da democracia como governo dos políticos.

A corrente pluralista também destacou a existência de um ofuscamento na concepção de Schumpeter, considerando esta como dicotômica por resumir a abrangência do cenário democrático aos cidadãos e aos políticos, sem considerar o leque de instituições e organizações que estão integradas na expressão da cidadania (N un, 2000, p. 37). Por outro lado, J essop observa que o marxismo também não considerou suficientemente essa dimensão extra-econômica na reprodução da relação do capital, que foge do âmbito das relações de troca e que se encontra refletida em instituições como as ONGs. ${ }^{18}$

Um outro aspecto limitado na concepção minimalista de democracia é a combinação igualdade/liberdade. Para Schumpeter, a igualdade pode ser medida no nível de competição. Ou seja, quanto mais igualdade houver na competição entre os grupos que disputam o voto do eleitor, mais democrático será o governo (Schumpeter, 1961, p. 327). 0 status fundamental que a cidadania detém, a partir do século $X V I I$, tem como elemento fundamental a igualdade. Entretanto, a sociedade de classes que caracteriza o capitalismo emergente nos séculos XIII eXIX impediu que a expressão da cidadania viesse a abalar a desigualdade econômica entre as classes. Para M arshall, ao impor direitos civis sob uma perspectiva universalista, a cidadania acabou por criar 0 indivíduo empreendedor e deixado à própria sorte na condução de sua vida. A ssim, ainda que tenha abal ado a estrutura de classes fundada na diferença de status entre os indivíduos, a cidadania não afetou as diferenças de classes impostas pela desigualdade econômica ( $\mathrm{M}$ arshall, 1967, p. 78-79).

18. Ver: Globalização, regionalização, mercado e o Estado: entrevista com Bob Jessop. Currículo sem Fronteiras, v. 2 , n. 2, jul./dez. 2002. A cesso em: http://www.curriculosem fronteiras.org/artigos.htm. 
É sob a luz do fenômeno da desigualdade nas sociedades capital istas contemporâneas que B orón equi para os traços que caracterizam uma organização sob a égide do mercado e da democracia. Em um nível mais profundo e abrangente que a teoria procedimentalista, a noção de igualdade desse autor refere-se à conquista de direitos sociais da sociedade civil através da participação popular - elemento inexistente na teoria schumpeteriana de democracia. A lógica da democracia é, nessa perspectiva, incompatível com a dos mercados. A primeira, ascendente, legitimar-se-ia no povo e é constituída na base. A segunda, descendente, baseia-se no consumo e tem os interesses moldados por oligopólios privados (B orón, 2001, p. 176).

Essa articulação nacional da sociedade civil ocorrida no B rasil contra os transgênicos, que tem seu ápice durante os anos 90, ainda que não tenha atingido o seu objetivo pleno, que era o estabelecimento de uma moratória ou a proibição imediata da comercialização dos alimentos dessa natureza no país, terá grande mérito na recente medida provisória do governo Lula. Esta reconheceu a soja transgênica como ilegal e estabeleceu que aquela que se encontra no mercado tenha um prazo de validade até 0 início de 2004. A inda que não tenha consolidado uma vitória da sociedade civil brasileira na luta contra a liberação indiscriminada dos transgênicos, essa lei pode ser considerada um grande avanço para os que se posicionaram pela precaução sanitária e ambiental, já que determinou ainda instrumentos de punição àqueles que, passado o período estipulado, não tenham se adaptado à legislação (Isto É, 9/7/2003, p. 7-11).

M esmo que o discurso do atual governo sustente na área agrícola um model o econômico alternativo à agricultura 'industrial' , predatória e custosa, que tem predominado em países como o nosso, seria al go muito mais complexo uma definição formal contra o cultivo dos transgênicos sem o engajamento e 0 apoio intenso de setores importantes do terceiro setor, tendo em vista a forte influência do agronegócio na economia e na política brasileiras, e a simpatia expressada por esse setor no debate sobre os transgênicos que se desenvolveu ao longo da década de 1990 (G lobo Rural, set./2001, p. 14).
Todavia, o reconhecimento do poder de mobilização do terceiro setor no alargamento das instâncias de participação popular em uma democracia capitalista como a brasileira, é preciso que se ressalte, não alivia a responsabilidade de todos os cidadãos no plano da el eição formal de representantes públicos coerentes com o interesse público. U ma conquista concretizada com base na contribuição da intervenção di reta da sociedade civil é salutar, especialmente em países como o Brasil, onde ainda há inúmeros mecanismos de restrição que separam os indivíduos do exercício da cidadania. M as a dinâmica el eitoral transforma cenários e frustra expectativas tão rapidamente quanto os constrói.

Portanto, paral elamente ao reconhecimento da legitimidade do terceiro setor como ator político fortal ecedor das democracias liberais, é preciso não menosprezar o valor das instituições de representação oficiais do modelo democrático de que dispomos. Compreendidas como parte integrante de um rol de conquistas da sociedade civil nas últimas décadas, a serem consolidadas, ampliadas e aperfeiçoadas, essas instâncias são, ao mesmo tempo, um ponto de chegada e um ponto de partida da emancipação social.

\footnotetext{
A bstract: In this article, we relate the Participacionismo and the Minimalismo, two democratic paradigms contemporaries, with the effective transformations in the capitalist economies. With base in this, we analyze the paper of the Third Sector in the social mobilization against the commercial release of the transgenicos in Brazil. The study if it withholds between 1998 and 2001, year where the MPF/DF suspends the indiscriminate authorizations for the alture of oavs in the country, and privileges the State of the Rio Grande do Sul, which we consider pioneer in the mobilization against the transgênicos.
}

K eys-words: democracy, third sector, participation politics.

\section{Referências}

A M A NHÃ . Porto A legre, outubro de 1997.

BORÓN, A tílio. Os novos L eviatãs e a polis democrática. In: A coruja de Minerva. M ercado contra democracia no capitalismo contemporâneo. Petrópolis: Vozes, 2001. p. 173-224. 
DA HL, Robert. Poliarquia. São Paulo: Edusp, 1997. p. 31.

ESTADO DE SÃ O PAUL 0, 8 de julho de 2001. p.A14

FER NANDES, Rubem César. Privado, porém público - o terceiro setor na $A$ mérica. $L$ atina. $R$ io de J aneiro: Relume-Dumará, 1994, p. 11-32.

GL OB O RURA L. Transgênicos - Disputa acirrada, ano 16, n. 191, set/2001.

ISTO É. M arina vai à luta. Entrevista com a ministra brasileira do M eio A mbiente, n. 1762, 9/7/2003, p. 711.

JESSOP, B ob. The democratic State and the national interest. In: State theory. Putting capital ist States in their place. University State Pensylvania, The Pensylvania State U niversity Press, 1990, cap. VI, p. 170-195.

LEWGOY, Flávio. A voz dos cientistas. História, Ciências, Saúde - Dossiê Transgênicos, v. 7, n. 2, jul./out./2000.

M ACPHERSON, C. B. A democracia liberal. Rio de J aneiro: Zahar, 1978.

MARSHAL, T. H. Cidadania e classe social. In: Cidadania, classe social e status. Rio de J aneiro: Zahar, 1967.

MENASCHE, Renata. U ma cronologia a partir de recortes de jornais. História, Ciências, Saúde DossiêTransgênicos, v. 7, n. 2, jul-out 2000.
M ONTENEGRO, Thereza. 0 que éONG? São Paulo: B rasiliense, 1994, p. 7-27. [C oleção Primeiros Passos, 24].

NUN, José. Democracia, gobierno del pueblo o gobierno de los políticos? Buenos A ires: Fondo de Cultura, 2000.

OLSON, M ancur. A lógica da ação coletiva. São Paulo: Edusp, 1999. [Clássicos, 16].

OTHWAITE, Tom. Dicionário do pensamento social do século XX. Rio de Janeiro: Jorge Zahar. Ed.1996.

PINHEIRO, Sebastião. Transgênicos: o fim do gênesis. Porto A legre: Fundação J uquira Candiru, 1999.

PATEM A N, Carole. The civic culture: a philosophic critique. In.: A L M OND, Gabriel \& VERBA, Sidney (Orgs.). The civic culture revisited. London: Sage, 1989.

SAES, Décio. A democracia como regime político burguês. In: Democracia. São Paulo: Á tica, 1993, p. 61-65.

SCHUM PETER, J. A. Capitalismo, socialismo e democracia. Rio de J aneiro: Fundo de Cultura, 1961. ZERO HORA. Caderno Campo \& Lavoura, Porto A legre, 14.9.1988, p. 26. 25.9.1988, p. 36.

. Caderno Campo \& Lavoura, Porto A legre, ZERO HORA. Caderno Campo \& Lavoura, Porto A legre, 25.9 e 17.10.1988. 